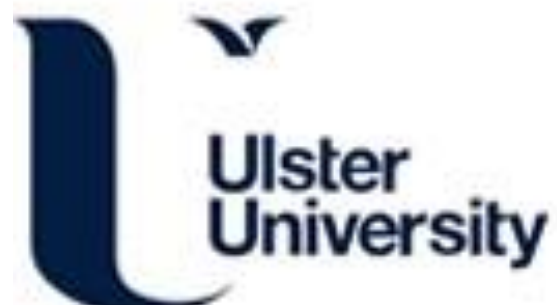

\section{Efficacy of resveratrol encapsulated microsponges delivered by pectin based matrix tablets in rats with acetic acid-induced ulcerative colitis}

Gandhi, H., Rathore, C., Dua, K., Vihal, S., Tambuwala, M. M., \& Negi, P. (2020). Efficacy of resveratrol encapsulated microsponges delivered by pectin based matrix tablets in rats with acetic acid-induced ulcerative colitis. Drug Development and Industrial Pharmacy, 46(3), 365-375.

https://doi.org/10.1080/03639045.2020.1724127

Link to publication record in Ulster University Research Portal

Published in:

Drug Development and Industrial Pharmacy

Publication Status:

Published (in print/issue): 03/03/2020

DOI:

10.1080/03639045.2020.1724127

\section{Document Version}

Author Accepted version

\section{General rights}

Copyright for the publications made accessible via Ulster University's Research Portal is retained by the author(s) and / or other copyright owners and it is a condition of accessing these publications that users recognise and abide by the legal requirements associated with these rights.

\section{Take down policy}

The Research Portal is Ulster University's institutional repository that provides access to Ulster's research outputs. Every effort has been made to ensure that content in the Research Portal does not infringe any person's rights, or applicable UK laws. If you discover content in the Research Portal that you believe breaches copyright or violates any law, please contact pure-support@ulster.ac.uk. 


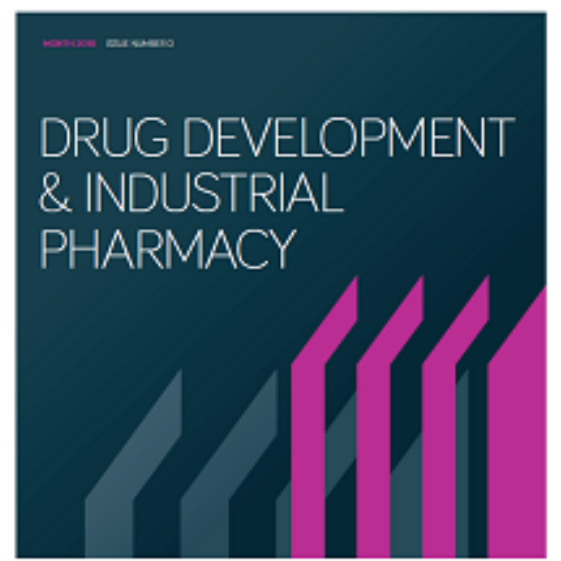

\section{Efficacy of resveratrol encapsulated microsponges delivered by pectin based matrix tablets in rats with acetic acid induced ulcerative colitis}

\begin{tabular}{|r|l|}
\hline Journal: & Drug Development and Industrial Pharmacy \\
\hline Manuscript ID & LDDI-2019-OR-0224.R1 \\
\hline Manuscript Type: & Original Research Paper \\
\hline Date Submitted by the & 10 -Oct-2019 \\
\hline Complete List of Authors: & $\begin{array}{l}\text { Gandhi, Himanshu; Shoolini University } \\
\text { Rathore, Charul; Shoolini University } \\
\text { Dua, Kamal; University of Technology Sydney; The University of } \\
\text { Newcastle Faculty of Health and Medicine } \\
\text { Vihal, Samar; Shoolini University } \\
\text { Tambuwala, Murtaza; University of Ulster, } \\
\text { Negi, Poonam; Shoolini University }\end{array}$ \\
\hline Keywords: & $\begin{array}{l}\text { Bioavailability, chitosan, Box-behnken design, quasi emulsion solvent } \\
\text { diffusion method, ulcerative colitis, release kinetics, pectin }\end{array}$ \\
\hline &
\end{tabular}

\section{SCHOLARONE Manuscripts}




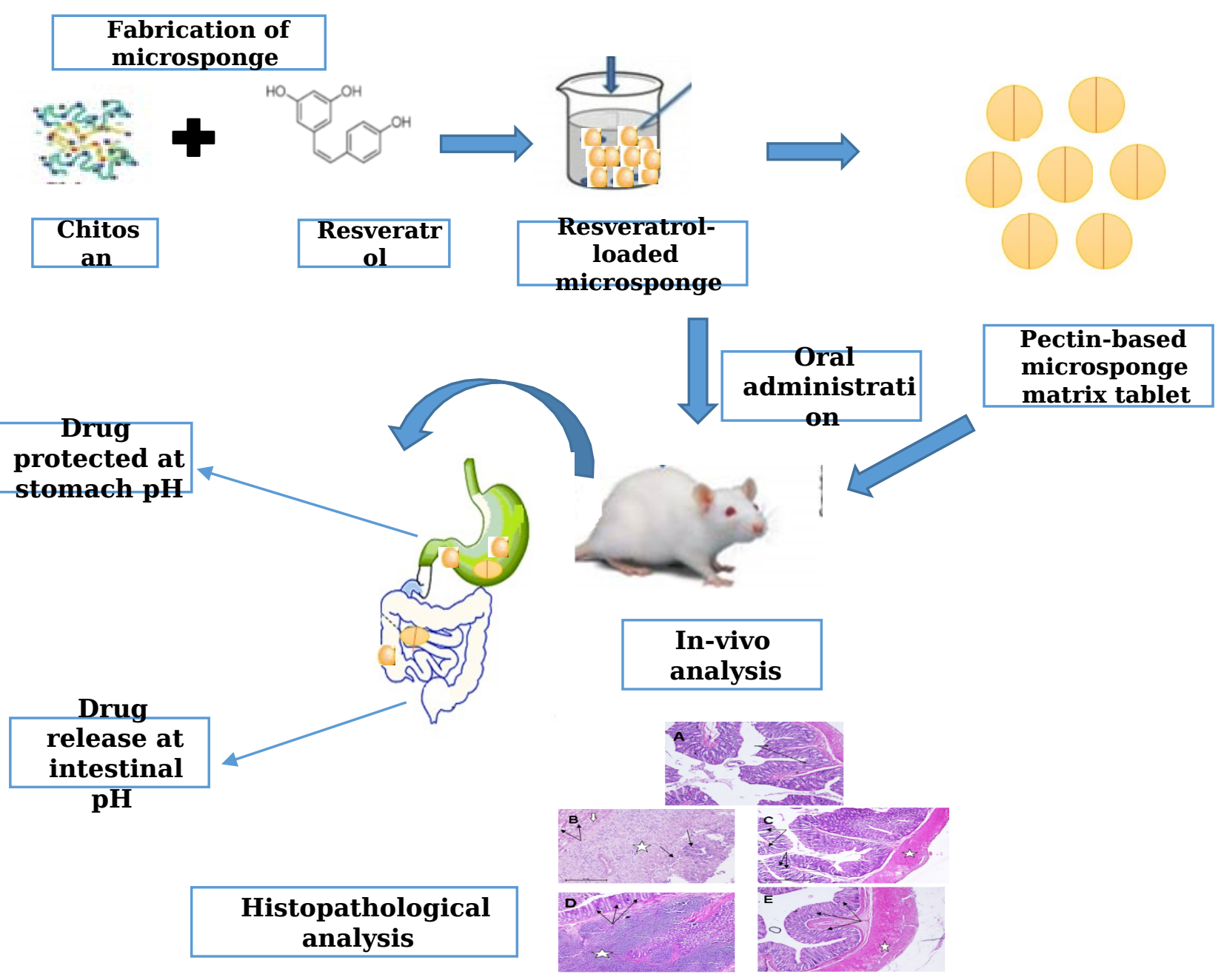




\title{
Efficacy of resveratrol encapsulated microsponges delivered by pectin based matrix tablets in rats with acetic acid-induced ulcerative colitis
}

\author{
Himanshu Gandhi ${ }^{1}$, Charul Rathore ${ }^{1}$, Kamal Dua1 ${ }^{2,3}$, Samar Vihal ${ }^{1}$, Murtaza M. \\ Tambuwala $^{4}$ and Poonam Negi ${ }^{1 *}$,
}

${ }^{1}$ School of Pharmaceutical Sciences, Shoolini University of Biotechnology and Management Sciences, Solan-173 212, Himachal Pradesh, India
${ }^{2}$ Discipline of Pharmacy, Graduate School of Health, University of Technology Sydney, Ultimo NSW 2007, Australia
${ }^{3}$ School of Biomedical Sciences and Pharmacy, The University of Newcastle, Callaghan, NSW 2308, Australia \& Priority Research Centre for Healthy Lungs, Hunter Medical Research Institute, Lot 1 Kookaburra Circuit, New Lambton Heights, Newcastle, NSW 2305, Australia
${ }^{4}$ School of Pharmacy and Pharmaceutical Sciences, Ulster University, Coleraine, Co. Londonderry, United Kingdom

\section{*To whom correspondence should be addressed}

Dr.PoonamNegi

M.S. Pharm, Ph.D

Professor of Pharmaceutical Science

School of Pharmaceutical Science

Shoolini University, Solan173212, India

E-mail: poonamgarge@gmail.com 
Abstract

Objectives: The objective of the present work to encapsulate the resveratrol (RES) inside the chitosan-based microsponges, employing the systematic optimization by $3^{3}$ Box-Behnken design for the colonic targeting.

Significance: Enhanced therapeutic efficacy of RES-loaded microsponges and matrix tablets, vis-a-vis pureRES for ulcerative colitis.

Methods: RES-loaded microsponges were prepared employing the systematic optimization by $3^{3}$ Box-Behnken design for the colonic targeting. The best-optimizedRES-loaded microsponge was compressed in the form of a tablet, employing pectin as a matrix-forming material. The encapsulation of RES inside microsponge was confirmed by XRD, DSC and FT-IR. Further, both RES-loaded microsponges and matrix tablets were evaluated for in vitro release kinetics and further evaluated for in vivo ulcerative colitis animal model.

54 Results:Optimization experiments was obtained as the high value of $r^{2}$ (particle size $=$ $0.9999 ; \% \mathrm{EE}=0.9652 ; \% \mathrm{CDR}=0.9469)$ inferred excellent goodness of fit. SEM revealed nearly spherical and porous nature of RES-loaded microsponges. The in vitro release kinetic showed zero-order release for RES-loaded microsponges and Korsmeyer-Peppas model for matrix tablets.The pharmacodynamic studies, in ulcerative colitis rat model, indicated better therapeutic efficacy of drug-loaded microsponges and matrix tablets, vis-a-vis pure RES. Thus, the present study advocates the potential of RES based microsponges delivered by pectin based matrix tablet, in the treatment of various colonic disorders.

Conclusion: The present study proved that RES-loaded microsponges and matrix tablets based on chitosan and pectin, can be the ideal delivery system for colonic delivery of RES. 
Keywords:Chitosan;Box-behnkendesign;quasi emulsion solvent diffusion method; pectin; ulcerative colitis; release kinetics.

\section{Introduction}

Resveratrol (RES) (3,5,4'-trihydroxystilbene), is a non-flavonoid polyphenolic phytoalexin molecule, synthesized by various plant species like grapes, berries, and peanuts, in response to stress and microbial infections[1,2]. RES acts as a strong antioxidant by inhibiting reactive oxygen species (ROS) primarily by activating protein kinase and suppresses cyclooxygenase (COX-2), and lipid peroxidation. It has demonstrated its therapeutic roles as antiinflammatory, analgesic, cardio-protective, neuroprotective, chemo-preventive, and antiaging agents [3]. There are many reports available for its decent therapeutic efficacy for lower gastrointestinal (GI) diseases like ulcerative colitis, peptic ulcer, Crohn's diseases and colon cancer $[4,5]$. Despite of high oral absorption $(\sim 75 \%)$, the oral bioavailability of RES is less than $1 \%$, due to its extensive intestine and liver metabolism [6, 7]. Moreover, rapid absorption in the upper GI tract and pre-systemic metabolism subsequently results in the lower amount of drug reaching to the colon $[8,9]$. Thus, there is a necessity to develop an efficient drug delivery system for RES, which would be able to target the drug directly to the colon and prevent its release in the upper GI tract.

Novel drug delivery carrier systems viz. nanoparticles, nano-spheres, micro-particles, microspheres, beads and micro/nano-sponges based on various polymers, have been consumedfor colon-specific drug delivery[10-13]. These systems are, controlled by GI transit time, GI pressure differences, GI pH differences, and colonic bacterial enzymes [14]. In the recent past, polysaccharides that are particularly metabolised by the colonic flora have increased acceptance as a colon-specific drug delivery systems. Pectin, a linear polysaccharide is extensively used as a colon-specific matrix carrier due to some attractive features, viz. hydrophobicity, and ability to form gel, biodegradability, and persistence to intestinal enzymes. The other polymer in the polysaccharide class is chitosan, which is $\mathrm{pH}-$ sensitive and is used as a colon-specific carrier owing to its ability to restrict the drug release in the gastric $\mathrm{pH}$, and significantly release the drug at higher $\mathrm{pH}$ [15]. Based on the above considerations, the advantages of both chitosan and pectin for colon-specific delivery of RES were combined into a unit dosage form, wherein chitosan was employed in the form of microsponges, and pectin as a matrix-forming material. Microsponges have the competency to encapsulate and adsorb a high degree of active ingredients onto its surface owing to numerous interconnected pores. Apart from high drug entrapment, and site-specificity, 
microsponges have a specific property of retaining on the surface of the colon, and thereby, increase the absorption of the drug in the colon $[16,17]$. Further, it can prevent the drug from early absorption, as the drug is enclosed inside the micro-sponge, and also the frequency of dosing may be decreased via controlled delivery of drug over a longer period of time, and hence the patient compliance [18].

Polymeric erosion based matrix systems comprising of hydrophilic polymer is highly popular in tablet manufacturing for controlled release application. Such matrix system, retard the drug release, owing to the formation of the gelatinous surface layer due to swelling in the aqueous medium, which controls the diffusion of water when placed in an aqueous medium[19, 20]. The present work was designed to systematically optimize the RES-loaded chitosan microsponges employing Box-behnken design with respect to particle size, entrapment efficiency, and percent cumulative drug release. The best-optimized RES loaded microsponge formulation was developed into the erosion based matrix tablet employing pectin. Finally, all the RES formulations were evaluated employing an acetic-acid induced ulcerative colitis model in rats.

\section{Experiment}

\section{Materials}

RES was received ex gratis from Tirupati Medicare Ltd., PaontaSahib, Sirmaur, Himachal Pradesh, India. Acetone, sodium chloride, polyvinyl alcohol (PVA), sodium dihydrogen phosphate, potassium dihydrogen phosphate, sodium hydroxide $(\mathrm{NaOH})$, and pectin, were procured from Nice Chemical Pvt. Ltd., Cochin, India. Ethanol, and $\mathrm{HCl}$ were purchased from Merck Specialties Pvt. Ltd., Mumbai, India, while Span 80, was purchased from Qualikems Laboratory Reagents, New Delhi, India. Chitosan was purchased from Hi-Media Laboratory Pvt. Ltd., Mumbai, India, while, PVP K30, and microcrystalline cellulose (MCC), were obtained from Loba Chemical Pvt. Ltd., Mumbai, India.

\section{Methods}

\section{Fabrication and evaluation of microsponges}

Microsponge preparation was done by quassi-emulsion technique as previously reported by authors [21]. Methanol was employed as a solvent to dissolved RES. $0.1 \mathrm{~mL}$ of internal aqueous phase was added into the organic phase to form w/o primary emulsion. Herein, the 
internal phase comprised of $1 \%(\mathrm{w} / \mathrm{v})$ aqueous solution of $\mathrm{NaCl}$ (as porogen) and Span 80 .

The organic phase was prepared in the DCM. Separately, chitosan was dissolved in minimum amount of $1 \% \mathrm{w} / \mathrm{v}$ aqueous solution of the glacial acetic acid solution, and RES was dissolved in methanol. Both the solution was then added to the required volume of DCM to form the organic phase. Finally, primary w/o emulsion was added into $5 \% \mathrm{w} / \mathrm{v}$ aqueous PVA (external phase), to form $\mathrm{w} / \mathrm{o} / \mathrm{w}$ double emulsion. The prepared emulsion was then, continuously stirred for $2 \mathrm{~h}$ on a mechanical stirrer. Microsponges so prepared were filtered, dried at $60^{\circ} \mathrm{C}$, and stored in the desiccator until further use[22].

\section{Systematic optimization of microsponges as per the experimental design}

RES-loaded microsponges were optimized employing three factor three-level, Box-Behnken design (BBD). The dependent variables were the amount of RES (X1), polymer (X2), and solvent (X3), used at three different levels of each variable, viz. low (-1), intermediate (0), and high $(+1)$. Various microsponge formulations (Table 1) prepared as per the design were investigated for the response variables like particle size, percent cumulative drug release $(\%$ $\mathrm{CDR})$, and percent entrapment efficiency (\%EE) as the response variables.

\section{Characterization of microsponges}

\section{Particle size determination}

The mean particle size of microsponge was analysed by Malvern Master Sizer (Scinrocco, 2000), installed at the University Institute of Pharmaceutical Sciences (UIPS), Chandigarh, India. All the samples were diluted 50 times before analysis. The samples were then placed into cuvettes and the intensity of fluctuation of the laser beam was recorded and interrelated with the particle size of the dispersed phase[23].

\section{Entrapment efficiency (\%EE), percentage yield (\%Y) and percentage drug loading(\%DL)}

For $\% \mathrm{EE}$, microsponge equivalent to $10 \mathrm{mg}$ of the drug were crushed and extracted employing methanol by ultra-sonication. To separate the insoluble residue, centrifugation was then carried out at $2000 \mathrm{rpm}$ for $10 \mathrm{~min}$. The supernatant was analysed by the U.V spectrophotometer (Systronics-Model-2202) at $\lambda_{\max } 302 \mathrm{~nm}$ after appropriate dilution [24]. To determine the concentration of RES, the value of absorptivity used was 1437 . The amount of \% EE, \% Y and \%DL was calculated employing the following Equations (1),(2) and (3) respectively. 
$\% E=\frac{\text { Mass of the drug in microsponge }}{\text { Initial mass of the drug }} \times 100(1)$

$\% Y=\frac{\text { Mass of the drug in microsponge }}{\text { Initial mass of the drug + Initial mass of polymer }} \times 100(2)$

$\% D L=\frac{\text { Mass of the drug in microsponge }}{\text { Mass of microsponge }} \times 100(3)$

\section{In vitro drug release}

170 In vitro dissolution study of RES for a period of $12 \mathrm{~h}$, from all the prepared microsponge formulations, was carried out employing the USP-Type-II dissolution apparatus(ElectrolabETC 11LX) [25]. Microsponges equivalent to $10 \mathrm{mg}$ of the RES, was placed in the jar, and the study was performed at different $\mathrm{pH}$, i.e. $\mathrm{pH} 1.2(200 \mathrm{~mL})$, for $2 \mathrm{~h}$, $\mathrm{pH} 6.8$ for $2-6 \mathrm{~h}$ and $\mathrm{pH} 7.4(700 \mathrm{~mL})$ for subsequent hours i.e., $6-12 \mathrm{~h}$ to simulate the same conditions of GIT. The stirring was maintained at $100 \mathrm{rpm}$ at $37 \pm 5^{\circ} \mathrm{Ctemperature.} \mathrm{Samples} \mathrm{(5}$ $\mathrm{mL})$ were withdrawn periodically at regular time intervals $(0,0.51 .5,2,3,4,6,8,10,12 \mathrm{~h})$ while an equal volume of fresh medium was added to maintain the sink conditions. The samples were diluted with methanol and analysed spectrophotometrically at $\lambda_{\max } 302 \mathrm{~nm}$ to calculate the percent cumulative drug release $(\% \mathrm{CDR})$ values [26].

\section{Optimisation data analysis and validation}

181 The optimization and validation of data obtained for various response variables viz., particle 182 size, \%EE, and \%CDR were performed employing mathematical modelling. The secondorder quadratic polynomial model was selected using multiple linear regression analysis (MLRA) to study the probability of a significant interaction(s) among the response variables[27, 28]. The response surface analysis was studied employing three dimensional (3D) response surface plots, and two-dimensional (2D) contour plots, constructed using Design Expert ${ }^{\circledR}$ ver.10.0.1 (Stat-Ease Inc., Minnepolis, MN). The numerical optimization using desirability function by 'trading off' of the response variables was employed to select the optimum microsponge formulation (RES:340 mg; polymer; $455 \mathrm{mg}$ ). A total of ten check-point microsponge formulations were selected and evaluated. The observed and predicted values for the studied responses, i.e. particle size, \%CDRand $\% \mathrm{EE}$, were critically compared. Percent bias (percent error) was determined with respect to the observed responses and the residual plots were also generated.

\section{Characterization of the optimized microsponge formulation}


195

196

197

198

199

200

201

202

203

204

205

206

207

208

209

210

211

212

213

214

215

216

217

218

219

220

221

222

\section{Scanning electron microscopy}

To observe the surface of microsponge, dried samples were mounted on a metal stub using double-sided adhesive tape and sputter-coated with gold for 1 min. under vacuum and then observed under a scanning electron microscope (SEM) at $10 \mathrm{kV}$ (QUANTA 250, FEI Makers, Singapore), installed at IIT, Mandi, H.P, India[27].

\section{Differential scanning calorimetric (DSC) analysis}

DSC (STA 449 F1 Jupiter) thermal analysis was carried out, on the optimized RES-loaded microsponge formulation, pure RES, and chitosan. Approximately $5 \mathrm{mg}$ sample was weighed, and sealed into aluminium pans. All the samples were heated at the rate of $10^{\circ} \mathrm{C} / \mathrm{min}$ in a temperature range of $25-300^{\circ} \mathrm{C}$, in nitrogen atmosphere [29].

\section{Thermal gravimetric analysis (TGA)}

TGA (STA449F1 Netzsch) thermal analysis was carried out, on the optimized RES-loaded microsponge formulation, pure RES, and chitosan. Approximately $5 \mathrm{mg}$ sample was weighed, and sealed into aluminum pans. The experiment was conducted in temperature range of $25-$ $300^{\circ} \mathrm{C}$ at a heating rate of $10^{\circ} \mathrm{C} / \mathrm{min}$ in a temperature range of $25-300^{\circ} \mathrm{C}$, in a nitrogen atmosphere $(20 \mathrm{ml} / \mathrm{min})[29,38]$.

\section{X-ray powder diffraction (XRD) study}

XRD was recorded to characterize the crystal and physical state of microsponge, pure RES and chitosan. The instrument (SmartLab $9 \mathrm{~kW}$ rotating anode $\mathrm{x}$-ray diffractometer) was operated at a voltage of $45 \mathrm{mV}$ and current $20 \mathrm{~A}$, and the diffraction patterns over a range of 5$10^{\circ} \mathrm{C} / \mathrm{min}$ in terms of $2 \varnothing[29]$.

\section{Formulation and evaluation of colon-targeted matrix tablet}

Colon targeted matrix tablets of optimized RES-loaded microsponges were prepared by direct compression method. Pectin (150 mg, matrix diluent), optimized microsponge formulation (150 mg),polyvinyl pyrollidine (PVPk30) (binder, $150 \mathrm{mg}$ ), and microcrystalline cellulose (MCC, $50 \mathrm{mg}$ ) were accurately weighed and mixed uniformly to form a homogenous powder-mixture. The final mixture was then passed through sieve no. 22, and was directly compressed into tablets, employing Rotatory tablet punching machine (Cadmech. Pvt. 
223 Ltd.)[30].Tablets were evaluated for various pharmacopoeial (weight variation, friability and 224 in vitro dissolution) and non- pharmacopoeial (hardness) aspects.

225 The in vitro dissolution of the matrix tablets was done as describes in section 2.4.3. The 226 weight variation of the matrix tablets was determined as per Indian Pharmacopoeia [31]. 227 Briefly, twenty tablets were weighed and the average weight was calculated. The percentage 228 of weight variation was also determined by using the following formula as shown in the 229 Equation. (4)

$$
\% \text { Weight Variation }=\frac{\text { Individual weight }- \text { Average Weight }}{\text { Average Weight }} \times 100(4)
$$

231 The friability of prepared matrix tablets was determined with Roche type friabilator. 10 tablets were weighed and tested at a speed of $25 \mathrm{rpm}$ for $4 \mathrm{~min}$. After the process was stopped, tables were removed out of the friabilator then after, dust was wiped-off, and tablets were weighed again. The difference between the weight before, and after, the process, was determined. The percentage friability (\%) was calculated using the following Equation (5)

$$
\% \text { Friability }=\frac{\text { Tablet weight before }- \text { Tablet weight after }}{\text { Tablet weight after }} \times 100(5)
$$

237 The hardness of the prepared matrix tablets was determined to employ Monsento hardness 238 tester. The hardness was measured in terms of force $\left(\mathrm{Kg} / \mathrm{cm}^{2}\right)$, required to break the tablet. 239 The tablet was placed between two anvils, the force was applied, until the tablet breaks and 240 this force was recorded. The hardness test was performed on twenty tablets, and the average 241 hardness was recorded [31].

\section{In vitro drug release kinetics}

243 Release data from the best-optimized microsponge formulation and its matrix tablet were 244 fitted to various mathematical models to study the drug release mechanisms. The various 245 models employed were zero-order (\% cumulative drug release vs. time) Equation(6), first246 order (log \% drug release vs. time) Equation (7), Higuchi model (\% cumulative drug release 247 vs. square root of time) Equation(8), and Peppas model (log \% drug release vs. log time) 248 Equation(9). The kinetic model was selected based on best fit with the highest value of the 249 regression coefficient $\left(\mathrm{r}^{2}\right)[7,21]$.

250 $Q_{t}=k 0 t$ 
251

252

253

254

255

256

257

258

259

260

261

262

263

264

265

266

267

268

269

270

271

272

273

274

275

276

277

278

279

280

281

$\ln Q_{t}=\ln Q_{\alpha+} k_{1} t$

$$
Q_{t}=k \sqrt{ } t(8)
$$

$Q_{t}=k_{\mathrm{k}} t^{(9)}$

Here $Q_{\mathrm{t}}$ is the amount of drug released at time $t, Q_{\alpha}$ is the initial amount of drug, whereas, $k_{0}$, $k_{1}, k$ and $k_{\mathrm{k}}$ are the corresponding release rate constants for zero-order, first-order, Higuchi and Korsmeyer-Peppas model respectively.

\section{In vivo pharmacodynamic study}

The animal study was carried out in prior approval of the Animal Ethical Committee, of Shoolini University Animal Ethics Committee, duly approved for the purpose of control and supervision of experiments on animals by the Government of India, (IAEC No/SUPHARM/7/10).

\section{Acetic acid-induced experimental ulcerative colitis in the colon}

Fifteen wistar albino rats (body weight $=160-200 \mathrm{~g}$ ), were taken, and caged individually with food and water ad libitum). The rats were distributed randomly into five groups with each group comprising of three animals. Except for the negative control group, colitis was induced in all the groups by intrarectal administration of $1 \mathrm{~mL}$ of $(4 \%)(\mathrm{v} / \mathrm{v})$ acetic acid, which resembles with the inflammatory bowel disease (IBD). The catheter was introduced into the anus up to a length of $6 \mathrm{~cm}$, and then acetic acid was administered [32]. The full IBD model was developed by keeping animals untreated for about three days [30]. After three days, each group received the treatment orally in $0.5 \%$ carboxymethyl cellulose $(\mathrm{w} / \mathrm{v})$ solution. Group 1 served as a negative control, group 2 served as colitis group without any treatment, group 3 received pure RES $(25 \mathrm{mg} / \mathrm{kg})$, group 4 received RES -loaded microsponges (equivalent to $25 \mathrm{mg} / \mathrm{kg}$ ), and group 5 received RES-loaded microsponge matrix tablets (equivalent to $25 \mathrm{mg} / \mathrm{kg}$ ) [33].

\section{Pharmacological Assessments}

After seven days of treatment, the animals were sacrificed and colon was removed, and based on inflammatory scales, and ulcer projections were visualized. The inflammatory scales were categorised as; $0=$ normal coloured colon, $0.5=$ red coloration, $1=$ spot ulcer, $1.5=$ haemorrhagic streaks, and $2=$ haemorrhagic ulcer.

\section{Histopathology assessment}


282 Histopathological analysis was performed by preserving the part of the colon in a $10 \%$ 283 formalin solution. These colonic sections were stained with hematoxylin and eosin (H\&E) 284 and examined using a light microscope with a fitted Nikon camera for the presence of any 285 necrosis, ulceration, haemorrhage, and inflammatory cell infiltration [34].

\section{Results and discussion}

\section{Formulation and optimization of microsponges}

288 In the present research, quassi emulsion technique was used to fabricate the various RES289 loaded microsponge formulations. Chitosan was employed as a polymer for the preparation 290 of microsponge due to its ability to release the drug, particularly at the colonic site. The 291 prompt mixing of w/o primary emulsion and water at the interface resulted in the 292 293 294 295

[Space for Table 1]

\section{Response surface mapping and data analysis}

299

The data analysis of the response variables employing second-order quadratic polynomial models $[27,28]$, suggested that the quadratic model was highly significant $(p<0.05)$ along 301 with the model terms $(\mathrm{p}<0.0001)$. The special polynomial mathematical model encompassing 302 ten coefficients $(\beta 0-\beta 33)$ represent quadratic and interaction terms, as shown in 303 Equation(10).

$Y=\beta 0+\beta 1 X 1+\beta 2 X 2+\beta 3 X 3+\beta 12 X 1 X 2+\beta 13 X 1 X 3+\beta 23 X 2 X 3+\beta 11 X 12+\beta 22 X 22+$ 305 B33X32 (10)

306 A very high degree of predictive ability of the optimization experiments was obtained as the 307 value of overall bias was $0.1109 \pm 0.2253 \%$. Further the high value of $\mathrm{r}^{2}$ (particle size $=$ 308 $0.9999 ; \% \mathrm{EE}=0.9652 ; \% \mathrm{CDR}=0.9469)$ inferred excellent goodness of fit. The residual plots were found to be uniform, comparatively narrow and random scatter around the zero-axis $[27,35]$.

\section{[Space for Table 2]}


312 Figure 1, depicts 2D-contour plots and corresponding 3D-response surface plots for \% EE 313 (A), \%CDR (B), and particle size (C). In the current studies, polymer and drug concentration 314 had a greater effect on all the studied response variables, out of all the studied input variables. 315 A curvilinear dip in the values of \% EE followed by an increasing trend was observed with an 316 increase in the drug concentration, and a decrease in polymer concentration as shown in 317 Figure 1A. In case of \%CDR, a twisted shape curve was observed with an increase in both 318 drug as well as polymer concentration as given in Figure 1B. An increase in polymer 319 concentration negatively influenced the \%CDR, while, an increase in drug concentration 320 enhanced the former. This can be attributed to the fact that the drug release from the polymer 321 matrix occurs after complete swelling of the polymer, and as the quantity of polymer in the 322 formulation increases, so the time required to swell also increases, and hence, slower the drug 323 release. In the case of particle size shown in Figure 1C, a linear relationship was obtained for 324 polymer and drug concentration. With the increase in polymer or drug concentration, particle 325 size was increased, however, the effect was more pronounced in case of polymer 326 concentration. The increase in the polymer concentration results in an increase in the 327 viscosity of the internal phase, which subsequently gives rise to the generation of more 328 viscous forces resisting droplet breakdown, and thus bigger sized particles. The search for 329 optimum microsponge formulation was carried out using numerical optimisation and 330 desirability function to get the required goals for the response variables. Table 3 presents the 331 constraint set for numerical optimisation. In model validation, a total of ten check-point 332 formulations were selected from the RSM. Hence, based on these parameters the best formulation was selected and further used for characterization.

[Space for Figure 1]

335

336

337

\section{[Space for Table 3]}

\section{Percentage yield (\%Y) and Drug loading (DL)}

The $\% \mathrm{Y}$ of all the prepared microsponges ranged between $69.45 \pm 0.52-86.68 \pm 0.67 \%$, while $\% \mathrm{DL}$ values were in the range of $40.1 \pm 0.34-71.45 \pm 0.76 \%$. With an increase in the drug concentration, $\% \mathrm{Y}$ and $\% \mathrm{DL}$ were found to be increased. This might be due to the high drug and polymer concentration, which led to increase in viscosity of the dispersed phase, and reduced the diffusion rate of DCM from viscous solutions into the aqueous phase, thus improving the yield and loading [36].

\section{Characterization of optimized formulation}




\section{Surface morphology}

346 The SEM image revealed formulation to be of nearly spherical shape having sufficient 347 surface porosity as shown in Figure 2a. The presence of numerous interlinked pores all over 348 the particle was also present imitating the spongy structure.

\section{$349 \quad$ X-ray powder diffraction (XRD) study}

350 The XRD pattern of pure RES, polymer, and optimized microsponge formulation were 351 recorded, and the overlay-XRD spectrum is shown in Figure 2b.RES showed numerous sharp 352 and intense diffraction peaks at 13.3, 16.4, 19.2, 22.4, 25.3, 28.3 and $45.3^{\circ}$, which indicates 353 crystalline nature at the respective $2 \varnothing$ positions. The polymer chitosan did not show any 354 peaks, suggesting its amorphous nature as depicted in literature. The microsponge 355 formulation also did not reveal any peaks of polymer and drug, indicating the entrapment of 356 drug inside the microsponges [29].

357

358 359

360 361

362

363

364

365

366

367

368

\section{FT-IR spectra}

The overlay FTIR spectra of RES, Chitosan and microsponge formulation is depicted in Figure 2c.RES exhibited three strong absorption bands at $1611 \mathrm{~cm}^{-1}, 1588 \mathrm{~cm}^{-1}$, and 1387.90 $\mathrm{cm}^{-1}$, analogous to $\mathrm{C}-\mathrm{C}$ aromatic double bond stretching, $\mathrm{C}-\mathrm{C}$ olefinic stretching, and C-C stretching, respectively. The peaks from 3167 to $3201 \mathrm{~cm}^{-1}$ depicts the $\mathrm{O}-\mathrm{H}$ stretching and the peak at $1561 \mathrm{~cm}^{-1}$ correspond to aromatic $\mathrm{C}=\mathrm{C}$ bending. The peak at $1447 \mathrm{~cm}^{-1}$ corresponds to C-C ring stretching [37]. The characteristic chitosan peaks belonging to its saccharide structure at 1055 and $898 \mathrm{~cm}^{-1}$ and at $1655 \mathrm{~cm}^{-1}$ (amide I) were close to the literature value. FTIR spectra of RES-loaded microsponges displayed all peaks analogous to pure RES and chitosan, however, with a decreased intensity of peaks. Further, the RES-loaded microsponges did not show any major peaks corresponding to the bioactive incorporated. This indicates the encapsulation of the RES within the microsponge formulation.

\section{Differential scanning calorimetric (DSC) analysis}

DSC thermograms of the drug, chitosan, and RES-loaded microsponge formulation are shown in Figure 2d. The drug RES demonstrated an endothermic peak around $260^{\circ} \mathrm{C}$, which is very close to the melting point of the drug, i.e., $261{ }^{\circ} \mathrm{C}$ to $263^{\circ} \mathrm{C}$. Chitosan revealed an endothermic peak, at around $220^{\circ} \mathrm{C}$, which is close to its reported value. In the case of microsponge formulation, there was no peak of RES and chitosan, which indicates the 
375

376

377

378

379

380

381

382

383

384

385

386

387

388

389

390

391

392

393

394

395

396

397

398

399

400

401

402

403

404

complete entrapment of drug inside the microsponge formulation and the amorphous state of microsponge formulation $[29,38]$.

\section{Thermal gravimetric analysis (TGA)}

TGA thermograms of the RES-loaded microsponge formulation, pure RES, and chitosan, are shown in Figure 2e. TGA thermograms of chitosan indicated the $\%$ weight loss of approximately $90 \%$ of the polymer ranges between $260-290^{\circ} \mathrm{C}$ as shown in figure $2 \mathrm{e}(\mathrm{A})$. whereas the $\%$ weight loss of drug found to be approximately $80 \%$ ranges between 220 $270^{\circ} \mathrm{C}$ has shown in figure $2 \mathrm{e}(\mathrm{B})$. Drug-loaded Optimized microsponge formulation showed TGA thermogram at a temperature range between $110^{\circ} \mathrm{C}-190^{\circ} \mathrm{C}$ signifying that the drug was either completely or partially changed into amorphous form [38].

\section{[Space for Figure2]}

\section{Evaluation of RES-loaded microsponge matrix tablets}

All the evaluation parameters of matrix tables are shown in Table 4 and suggest its satisfactory characteristics. The formulations exhibited a hardness of $4.13 \pm 0.13 \mathrm{~kg} / \mathrm{cm}^{2}$ and friability below $0.69 \pm 0.23 \%$ which showed satisfactory mechanical strength of the tablets. The average weight of the twenty tablets was found to be $499.65 \pm 1.35$ which is well within the IP limit of weight variation i.e. $( \pm 5 \%)$.

\section{[Space for Table4]}

\section{In vitro release of RES-loaded microsponges matrix tablets}

The in vitro release pattern of RES, from plain microsponges, and microsponge-matrix tablet is shown in the Figure 3. The rate of drug release in $12 \mathrm{~h}$ was gradually increased, with an increase in time, and then became constant or attained equilibrium, in optimized microsponge formulation. Drug release mechanisms from microsponge could be linked to its porous surface. The latter permits easy penetration of the release media, and its approachability to the entrapped drug. It was witnessed that the microsponge system was able to control the drug release in gastric $\mathrm{pH}$ i.e., only $10 \%$ of the drug was released during an initial $2 \mathrm{~h}$. However, the drug release from matrix tablets at all the $\mathrm{pH}$ conditions was on the lower side vis-à-vis microsponge formulation. This could be due to the slow swelling property of the pectin, followed by gradual erosion, and release of the drug from the matrix tablets $[17,21]$. It is well reported that the drug release from a swellable hydrophilic polymer like pectin can 
405 be controlled and relating the liquid penetration within the polymer matrix, the swelling of 406 the hydrated polymer, drug diffusion throughout the swollen matrix and, erosion. PVP due to 407 its water-soluble characteristic could help in the solubilization in the aqueous phase and helps 408 in the permeation of dissolution media through the matrix causing its erosion [21].

\section{[Space for Figure3]}

\section{$410 \quad$ Kinetic release analysis of drug}

411 The fitting of drug release data by suitable mathematical models is a powerful tool, which not 412 only enables the better interpretation, and comprehension of the mechanisms involved in the 413 drug release process but also helps in controlling the release features according to specific 414 therapeutic needs. Different mathematical models as shown in Table 5 were applied to in 415 vitro drug dissolution profiles and their respective coefficients were estimated.

416 According to $\mathrm{r}^{2}$ values, as shown in Table 5, it can be noted that the microsponge fitted better 417 with the zero-order kinetic model, while the microsponge tablets fitted best with the Peppas 418 model. In the Korsmeyer-Peppas model, the value of $\mathrm{n}$ specifies the release mechanism of the 419 drug as defined. For the case of spherical matrix tablets, $0.43 \leq$ n corresponds to a Fickian 420 diffusion mechanism, $0.43<\mathrm{n}<0.85$ to non-Fickian transport, and $\mathrm{n}>0.85$ to super case II 421 transport [35]. Here, the value of $\mathrm{n}$ was determined to be more than 0.85 , thus mimicking the super case II transport kinetics.

423 [Space for Table5]

\section{$424 \quad$ In vivo pharmacodynamic study}

After the completion of in vivo pharmacodynamic study, rats were sacrificed, and colon was 426 examined visually, on the basis of inflammatory scales as shown in Table $6[17,40]$. It is vivid from the results that there were less colonic lesions seen in the case of treated groups vis-à-vis colitis group, indicating positive therapeutic outcomes of RES, RES-loaded microsponge, and microsponge-matrix tablets.

\section{[Space for Table 6]}

\section{Histopathological studies}

433 All the histological pictures of various treated and untreated groups are depicted in Figure 4. 434 While negative control group as shown in Figure 4A, revealed healthy looking mucosal or 
435 sub-mucosal lining, and intact mucosal crypt, acetic acid-induced colitis group (Figure 4B) 436 showed severe surface, and mucosal haemorrhage (white arrows), marked necrotic 437 alterations, and leftovers of colonic crypts (black arrows). Besides, the sub-mucosal layer in 438 the acetic acid-induced colitis group revealed polymorphic inflammatory cell infiltration 439 (stars). Thus, it can be concluded that the colitis group revealed severe mucosal ulceration, 440 inflammatory cell infiltration, submucosal edema, and goblet hyperplasia [40] Figure 441 4Cpertaining to the pure RES treated group showed colonic mucosa with no haemorrhage 442 streak, mild preservation of crypts with slight dilations, and almost intact mucosal lining cells 443 (arrows). Microsponge formulation treated group, i.e. (Figure 4D), and microsponge-matrix 444 tablet treated group, (Figure 4E) revealed intact mucosal crypts, healthy mucosal and 445 submucosal lines, suggesting both the formulations to preserve the normal colonic condition. 446 However, RES-loaded microsponge treated group revealed much prominent results in 447 comparison to the microsponge-matrix tablet treated group. Overall, all the RES treated 448 groups exhibited the complete cure of ulcerative colitis after the 7th day [33].

\section{[Space for Figure 4]}

450

451

452

453

454

455

456

457

458

459

460

461

462

463

464

465

\section{Conclusion}

The present study successfully ratified that the chitosan microsponge were able to entrap the RES. The systemic optimization employing BBD aided in studying the most influential variables to select the best-optimized formulation. The in vitro release kinetics data revealed the sustained release nature of the developed systems. Finally, in the in vivo ulcerative colitis model, better therapeutic outcomes from drug-loaded microsponge, and microsponge loaded matrix tablets were achieved vis-à-vis pure RES. Overall, the present studies corroborated that the developed microsponges matrix system based on chitosan and pectin can be the ideal delivery system for colonic delivery of RES. 


\section{References}

[1] KasiotisKM,Pratsinis H, KletsasD. Resveratrol and related stilbenes: their anti-aging and anti-angiogenic properties. Food ChemToxicol. 2011;61:112-20 
[2] BaurJA, Sinclair DA.Therapeutic potential of resveratrol: the in vivo evidence. Drug Discovery. 2006;5(6):493-506.

[3] PangeniR,SahniJK,AliJ.Resveratrol: review on therapeutic potential and recent advances in drug delivery. Expert Opin Drug Deliv. 2014;11(8):1285-1298.

[4] Das S, Ng KY, Ho PC. Design of a pectin-based microparticle formulation using zinc ions as the cross-linking agent and gluteraldehyde as the hardening agent for colonic specific delivery of resveratrol: in vitro and in vivo evaluations. J Drug Target. 2011;19:446-57. doi.org/10.3109/1061186X.2010.504272

[5] Jeong JB, Lee J, Lee SH. TCF4 is a Molecular Target of Resveratrol in the Prevention of Colorectal Cancer. International journal of molecular sciences. 2015;10411-10425.

[6] Negi P, Aggarwal M, Sharma G, Rathore C. Niosome-based hydrogel of resveratrol for topical applications: An effective therapy for pain related disorder(s). Biomedicine \& Pharmacotherapy. 2017;88:480-487.

[7] Zu Y, Zhang Y, Wang W.Preparation and in vitro/ in vivo evaluation of resveratrolloaded carboxymethyl chitosan nanoparticles. Drug Delivery. 2014;1-11.

[8] Das S, Ng KY.Colon-specific delivery of Resveratrol: Optimization of multiparticulate calcium-pectinate carrier. International Journal of Pharmaceutics. 2010;35:20-28.

[9] Gabriel DP, McClements DJ. Resveratrol encapsulation: designing delivery Resveratrol encapsulation: designing delivery systems to overcome solubility, stability and bioavailability issues. Trends in food science and technology. 2014;38:88-103.

[10] Bonechi C, Martini S, Ciani L. Using liposomes as carriers for polyphenolic compounds: the case of trans-resveratrol. PLoS One. 2011;7:1-11. doi: org/10.1371/journal.pone.0041438.

[11] Zu Y, Zhang Y, Wang W, Zhao X, Han X, Wang K, et al. Preparation andin vitro/in vivoevaluation of resveratrol-loaded carboxymethyl chitosan nanoparticles. Drug Delivery. 2016;1-11. doi:10.3109/10717544.2014.924167

[12] LoftssonT, Brewster ME. Pharmaceutical application of cyclodextrins. Drug solubilization and stabilization. J Pharm Sci. 1996;85:1017-25.doi: org/10.1021/js950534b

[13] Peng X, Xiong H, Li J.Vanillin cross-linked chitosan microspheres for controlled release of resveratrol. J. food chem. 2010;121(1):23-28. doi: org/10.1016/j.foodchem.2009.11.085

[14] Pando D, Gutierrez G, Coca J.Preparation and characterization of niosomes containing resveratrol. J Food Eng.2013;117:227-34.

[15] Ahmed RZ, PatilG, ZaheerZ. Nanosponges- a completely new nano-horizon: pharmaceutical applications and recent advances.Drug Dev. Ind. Pharm. 2013;39(9):1263-72.

[16] Osmani RAM, Aloorkar NH. Microsponge based drug delivery system for augmented gastroparesis therapy: Formulation development and evaluation. Asian Journal Pharmaceutical Sci. 2015;10:442-451.

[17] Nief RA, Hussein AA. Preparation and Evaluation of Meloxicam Microsponges as Transdermal Delivery System. Iraqi Journal of Pharmaceutical Sci. 2014;23(2).

[18] Srivastava R, Kumar D, Pathak K. Colonic Luminal surface retention of meloxicam microsponges delivered by erosion based colon-targeted matrix tablet. International Journal of Pharm. 2012;427:153-62.

[19] MaheshwariR, SharmaP. Microsponge Embedded Tablets for Sustained Delivery of Nifedipine.PharmNanotechnol. 2017;5(3):192-202.

[20] Ashord M, Fell JT, Attwood D.An evaluation of pectin as a carrier for drug targeting to the colon. Journal of Control Release.1993;26:213- 220. 
[21] Maestrelli F, Zerroukm N, Cirri M. Comparative evaluation of polymeric and waxy microspheres for combined colon delivery of ascorbic acid and ketoprofen. International Journal of Pharm. 2015;485:365-373.

[22] Kumar V, Soni GC, Prajapati SK. Sustained Release Hydrophilic Matrix Tablet of Ibuprofen: Influence of Polymers on Invitro Release and Bioavailability. International Journal of Pharmaceutical Research and Sci. 2012;1(4):69-83.

[23] RathoreC, Jain N, Garg N. Polysaccharide-microsponge based matrix tablet for colon targeting of ketoprofen:In vitro and in vivo evidence. IJPSR. 2017;8(10):4250-4260.

[24] Perge L, Robitzer M, Guillemot C. New solid lipid microparticles for controlled ibuprofen release: formulation and characterization study. International Journal of Pharm. 2012;422:59-67.

[25] Shinde AJ, Paithane MB, Sawant SS. Development and Evaluation of Fenoprofen Microsponges and its Colonic Delivery using Natural Polysaccharides. Asian Journal of Pharmaceutical Sciences and Nanotechnol.2014;1(27):42-30.

[26] DevrimB, CanefeK.Preparation and evaluation of modified release ibuprofenmicrospheres with acrylic polymers (eudragit ${ }^{\circledR}$ ) by quasiemulsion solvent diffusion method: effect of variables. Acta Pol. Pharm. Drug Res. 2006;63:521-534.

[27] Anwer MK, Al-Shdefat R, Ezzeldin E, AlshahraniSM,Alshetaili AS, et al. Preparation, Evaluation and Bioavailability Studies of Eudragit Coated PLGA Nanoparticles for Sustained Release of Eluxadoline for the Treatment of Irritable Bowel Syndrome. Frontiers in Pharmacol.2017;8:844. doi:10.3389/fphar.2017.00844

[28] Negi P, Singh B, Sharma G. Phospholipid microemulsion-based hydrogel for enhanced topical delivery of lidocaine and prilocaine: QbD-based development and evaluation. Drug Deliv. 2016; 23(3);941-57. doi: 10.3109/10717544.2014.923067.

[29] Zu Y, Zhang Y, Wang W, Zhao X, Han X, Wang K and Ge Y. Preparation and in vitro/ in vivo evaluation of resveratrol-loaded carboxymethyl chitosan nanoparticles. Drug Delivery. 2014; 1-11.

[30] Negi P,Singh B, SharmaG..Enhanced Topical Delivery of Lidocainevia. EthosomesBased Hydrogel: Ex-vivo and In-vivo Evaluation. Journal of Nanopharmaceutics and Drug Deliv.2014;2(2):138-147

[31] Malipeddi VR, Awasthi R, Dua K. Formulation and evaluation of controlled-release matrix systems of ciprofloxacin.Polim Med. 2017;47(2):101-10628.

[32] Sareen R, Nath K, Jain N. Curcumin Loaded Microsponges for Colon Targeting inflammatory Bowel Disease: Fabrication, Optimization, and In vitro and Pharmacodynamic Evaluation. BioMed Research Int.2014;2014.

[33] Indian Pharmacopoeia (IP) 2014. Government of India Ministry of health \& Family Welfare, The Indian Pharmacopoeia commission, Ghaziabad. 2014: II: 1864-1866.

[34] TahanG, AytacE, AytekinH. Vitamin E has a dual effect of anti-infammatory and anti-oxidat activities in acetic-acid induced colitis in rats. Can J Surg. 2011;54(5):33338.

[35] Murad HAS, Abdallah HM, Ali SS. Menthalongifolia protects against acetic acid induced colitis in rats. Journal of Ethnopharm. 2016;1-22.

[36] Singh B, Kapil R, Nandi M. Developing oral drug delivery systems using formulation by design: Vital precepts, retrospect and prospects. Expert OpinDrugDeliv. 2011;8:1341-60.

[37] Fernanda MC, Ana DS, Raul CE.Insights into the swelling process and drug release mechanisms from cross-linked pectin/high amylose starch matrices. Asian journal of pharmaceutical sci. 2014;9:27-34. 
613 [38] Gupta A, Tiwari G, Tiwari R, Srivastava R, Rai AK. Enteric coated HPMC capsules plugged with 5-FU loaded microsponges: a potential approach for treatment of colon cancer. Brazilian Journal of Pharmaceutical Sciences. 2015;51(3):591-605.

[39] Esiringu F, Demiroz FT, AcarturkF.Investigation of the effect of intracolonic melatonin gel formulation on acetic acid-induce colitis. Drug Deliv. 2014;1-9.

619

620

621

622 


\section{List of figures legends}

Figure 1. Two-dimensional contour plots and corresponding three-dimensional response surface plot depicting the effect of various input variables on; (A) Entrapment Efficiency, (B) $\%$ CDR(cumulative drug release), and (C) Particle Size.

Figure 2. a) SEM image of resveratrol-loaded microsponge formulation (Magnification $8000 \mathrm{x}$ ) b) XRD spectra of drug, polymer and microsponge formulation c) FTIR spectra for resveratrol, chitosan and resveratrol-loaded microsponge formulation d) Heating curves of differential scanning calorimetry (DSC) for polymer, drug and microsponge formulation e) Thermal gravimetric analysis (TGA) of polymer, drug and microsponge formulation.

Figure 3. Comparision of $\%$ CDR between optimized resveratrol-loaded microsponge formulation and resveratrol-loaded microsponge-matrix tablet. Each cross bar indicates average value $\pm \mathrm{SD}(\mathrm{n}=3)$.

Figure 4. Histology of colonic section of (A) Normal control group, (B) Acetic acid-induced colitis group, (C) Resveratrol treated group, (D) Resveratrol-loaded microsponge treated group, (E) Resveratrol-loaded microsponge-matrix tablet treated group. 

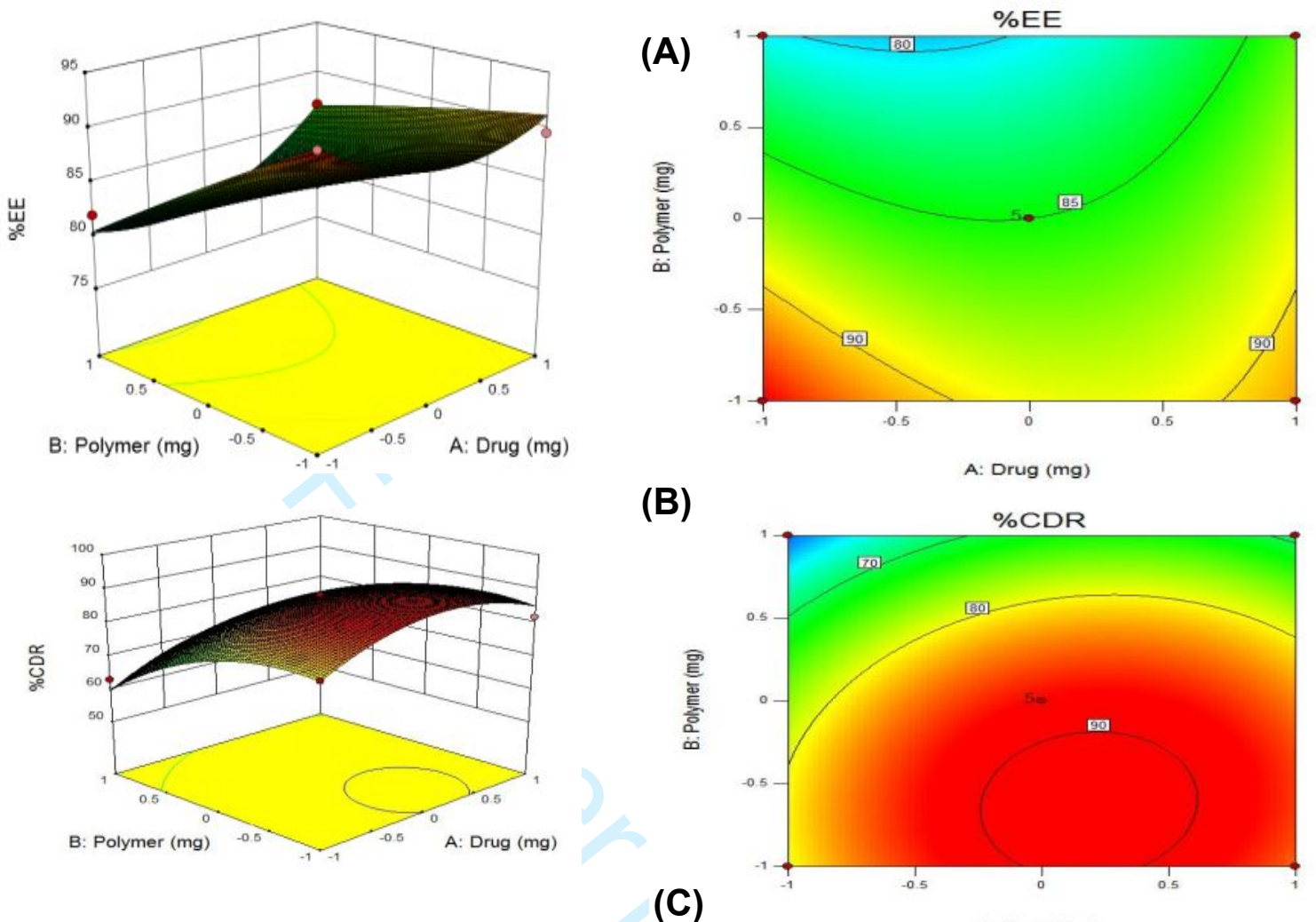

(C)
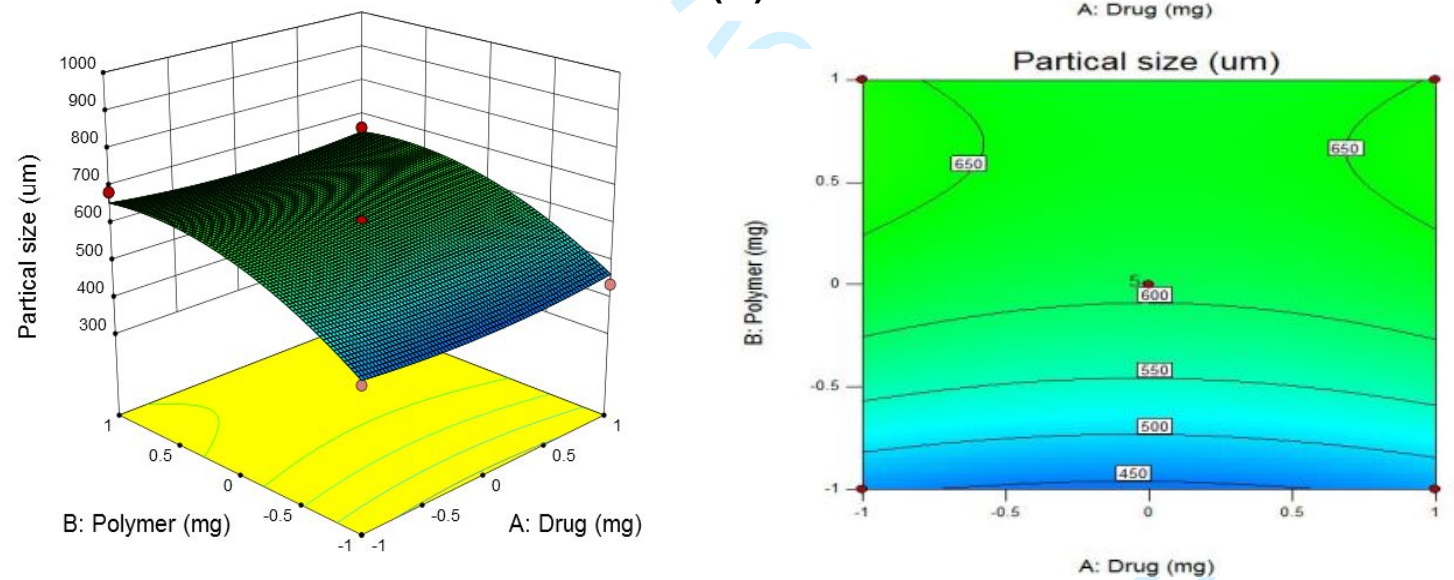

Fig. 1. Two-dimensional contour plots and corresponding three-dimensional response surface plot depicting the effect of various input variables on; (A) Entrapment Efficiency, (B) $\%$ CDR(cumulative drug release), and (C) Particle Size 


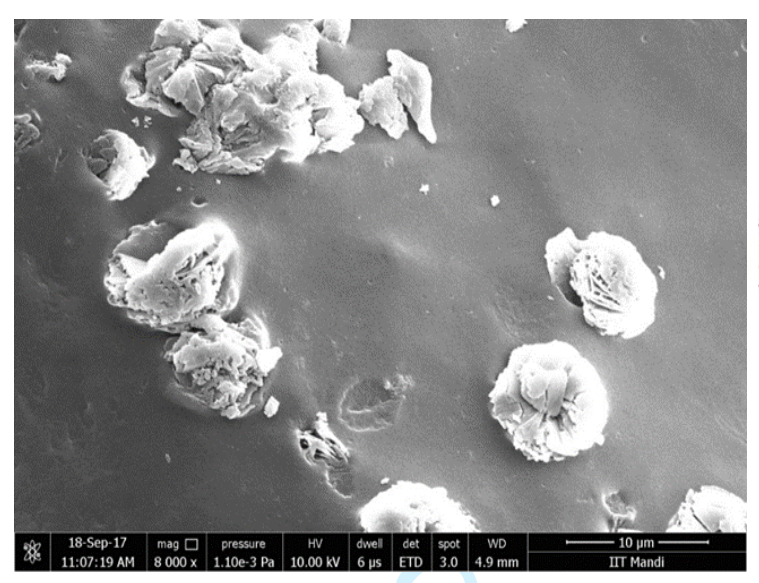

a)

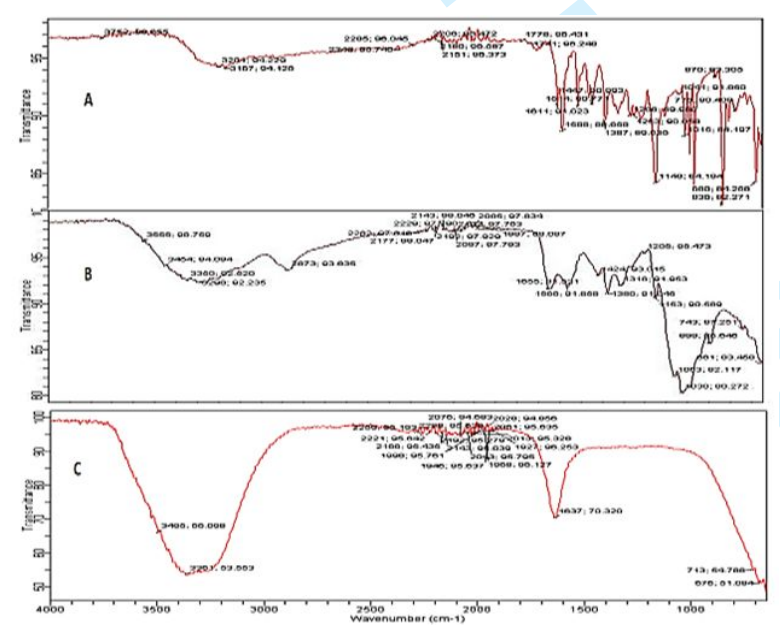

c)

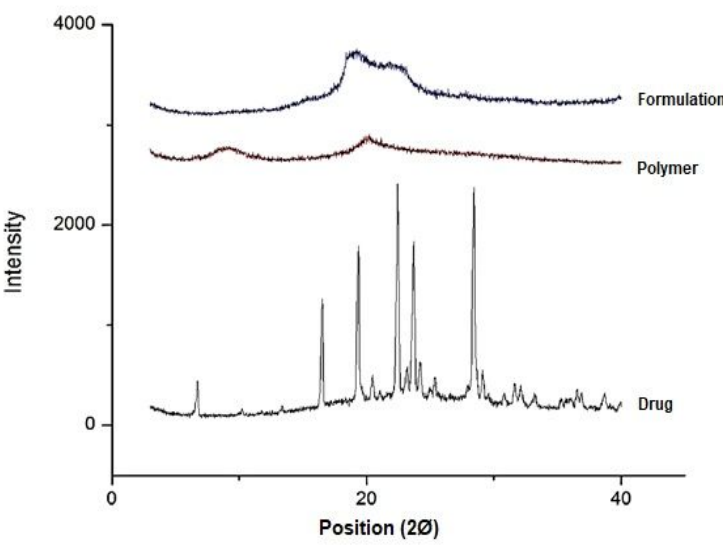

b)

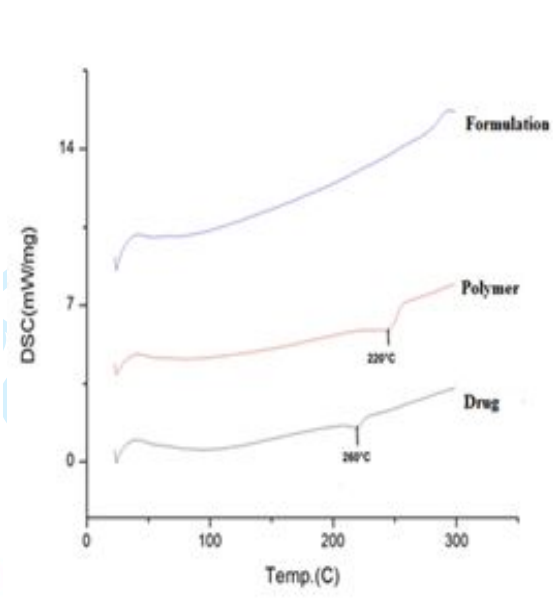

d)

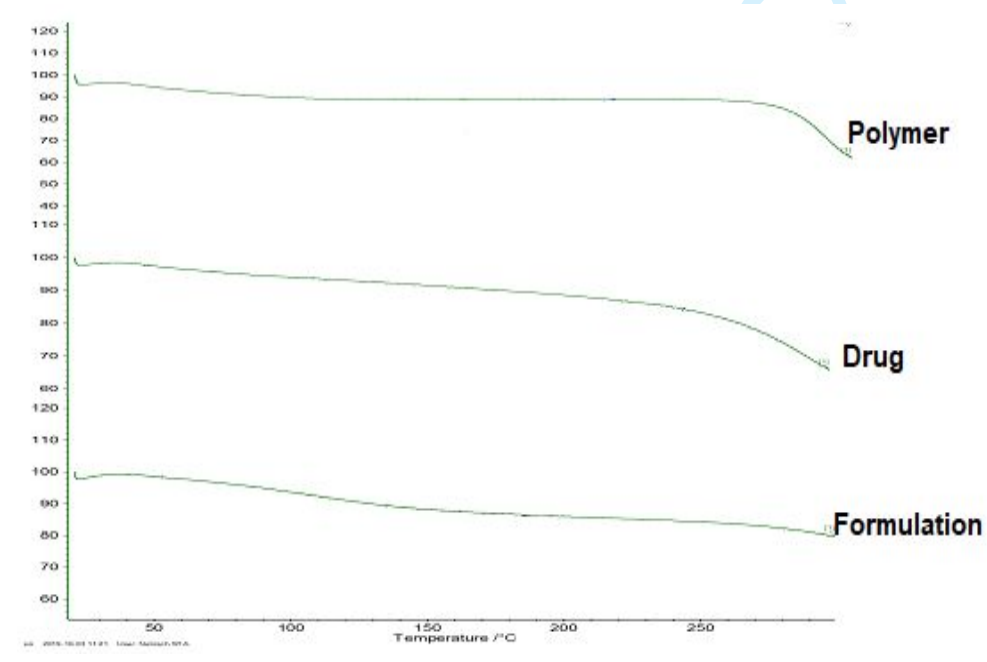

e) 
Fig. 2. a) SEM image of RES-loaded microsponge formulation (Magnification $8000 \mathrm{x}$ )b)XRD spectra of drug, polymer and microsponge formulation c)FTIR spectra for A) RESB) Chitosan and C) RES-loaded microsponge formulation d)Heating curves of differential scanning calorimetry (DSC) for polymer, drug and microsponge formulation e)Thermal gravimetric analysis (TGA) of polymer, drug and microsponge formulation..

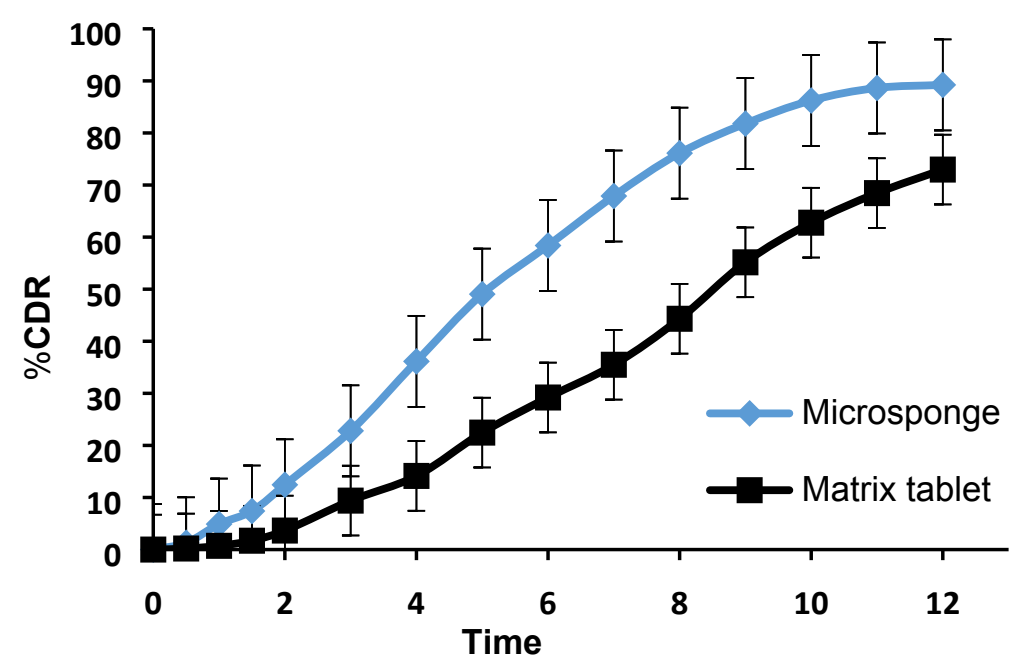

Fig. 3. Comparision of \% CDR between optimized RES-loaded microsponge formulation and RES-loaded microsponge-matrix tablet. Each cross bar indicates average value $\pm \operatorname{SD}(n=3)$. 


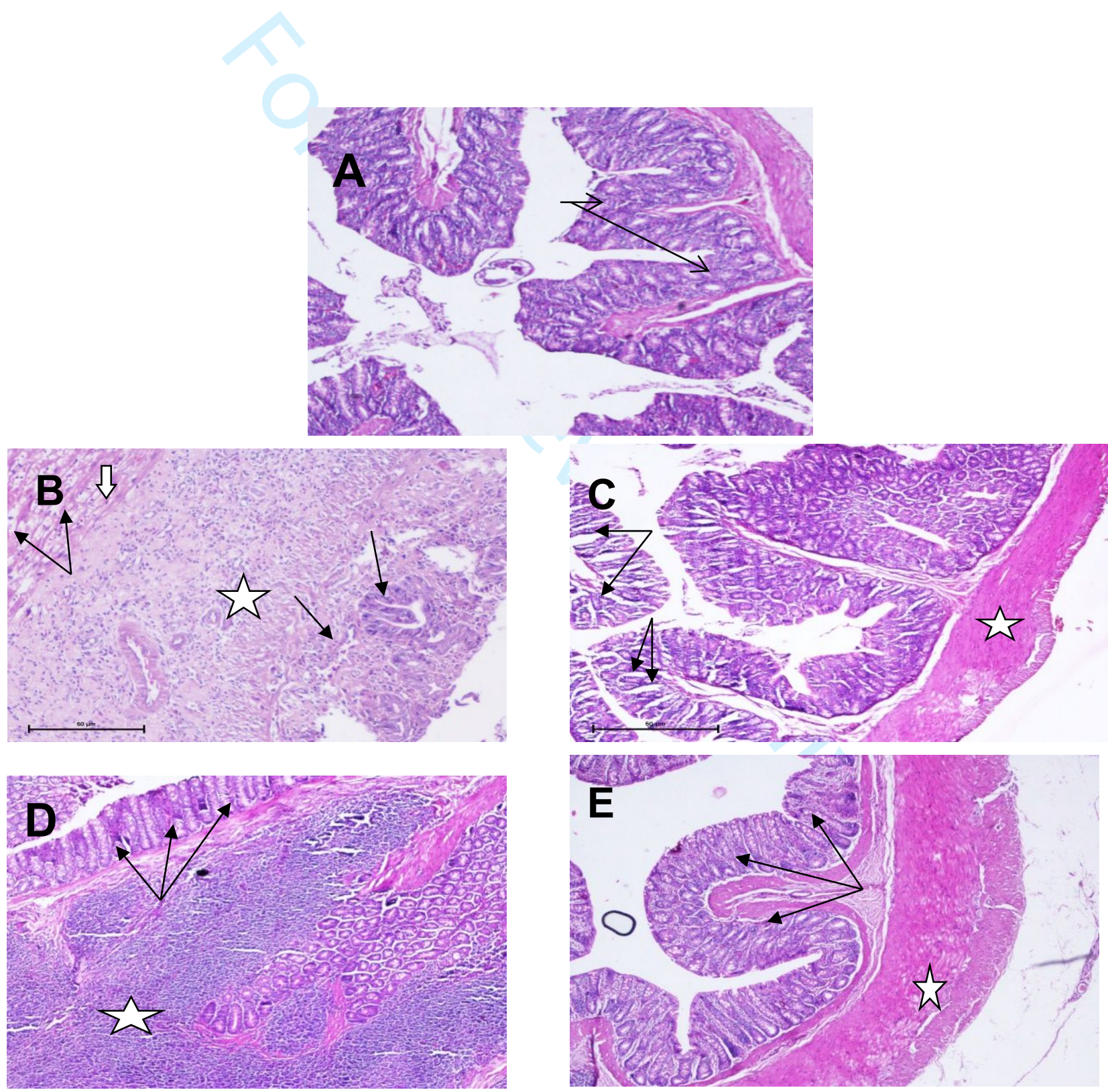

Fig. 4. Histology of colonic section of (A) Normal control group, (B) Acetic acid-induced colitis group, (C) RES treated group, (D) RES-loaded microsponge treated group, (E) RES-loaded microsponge-matrix 
tablet treated group.White arrow indicates severe surface, and mucosal haemorrhage, Black arrow indicates marked necrotic changes, and remnants of colonic crypts and Star indicates the sub-mucosal layer revealing polymorphic inflammatory cell infiltration 


\section{List of tables}

Table 1: Experimental runs of BBD design matrix and their responses

Table 2: Polynomial mathematical model data

Table 3: Constraints for numeric optimization and predicted solutions

Table 4: Various evaluation parameters of matrix tablets

Table 5: Regression cofficient values of microsponge matrix tablet and microsponge formulation Table 6: Macroscopic evaluation of colonic lesions of rat $(0=$ normal coloured colon, $0.5=$ red coloration, 1 = spot ulcer, $1.5=$ haemorrhagic streaks, and $2=$ haemorrhagic ulcer) 
Table 1. Experimental runs of BBD design matrix and their responses

\begin{tabular}{|c|c|c|c|c|c|c|}
\hline Runs & $\begin{array}{l}\text { Drug } \\
\text { (mg) }\end{array}$ & $\begin{array}{l}\text { Polymer } \\
(\mathrm{mL})\end{array}$ & $\begin{array}{l}\text { Solvent } \\
(\mathrm{mL})\end{array}$ & $\% \mathbf{E E}$ & $\%$ CDR & $\begin{array}{l}\text { Particle size } \\
(\mu \mathrm{m})\end{array}$ \\
\hline 1 & -1 & 0 & -1 & 82.8 & 68.47 & 464.172 \\
\hline \multirow[t]{2}{*}{2} & 1 & 1 & 0 & 8 & 68.88 & 663.563 \\
\hline & & & & 6.8 & & \\
\hline 3 & 0 & 0 & 0 & 85 & 88.18 & 609.211 \\
\hline 4 & 0 & 0 & 0 & 85 & 88.18 & 609.211 \\
\hline 5 & 1 & 0 & -1 & 83 & 81.74 & 471.391 \\
\hline 6 & 0 & 1 & -1 & 76 & 56.96 & 378.227 \\
\hline 7 & -1 & -1 & 0 & 94 & 80.30 & 446.452 \\
\hline 8 & -1 & 0 & 1 & 87 & 70.71 & 853.771 \\
\hline 9 & 1 & -1 & 0 & 89.6 & 81.8 & 436.582 \\
\hline 10 & 0 & 0 & 0 & 85 & 88.18 & 609.211 \\
\hline 11 & 0 & 1 & 1 & 79 & 72.48 & 923.211 \\
\hline 12 & 0 & 0 & 0 & 85 & 88.18 & 609.211 \\
\hline 13 & -1 & 1 & 0 & 82 & 62.97 & 686.98 \\
\hline 14 & 1 & 0 & 1 & 93 & 78.52 & 869.236 \\
\hline 15 & 0 & -1 & -1 & 84.6 & 87.61 & 395.606 \\
\hline 16 & 0 & 0 & 0 & 85 & 88.18 & 609.211 \\
\hline 17 & 0 & -1 & 1 & 92 & 84.64 & 600.834 \\
\hline
\end{tabular}

\begin{tabular}{lccc}
\hline Independent variables & \multicolumn{3}{c}{ Level used, actual (coded) } \\
\cline { 2 - 4 } & Low $(-1)$ & Medium $(1)$ & High $(+1)$ \\
\hline Drug & 250 & 375 & 500 \\
\hline Polymer & 250 & 375 & 500 \\
\hline Solvent & 2.5 & 5 & 7.2 \\
\hline
\end{tabular}




\begin{tabular}{|c|c|c|c|c|c|c|}
\hline Runs & $\begin{array}{l}\text { Drug } \\
\text { (mg) }\end{array}$ & $\begin{array}{l}\text { Polymer } \\
(\mathrm{mL})\end{array}$ & $\begin{array}{l}\text { Solvent } \\
(\mathrm{mL})\end{array}$ & $\% \mathrm{EE}$ & $\% \mathrm{CDR}$ & $\begin{array}{l}\text { Particle size } \\
(\mu \mathrm{m})\end{array}$ \\
\hline 1 & -1 & 0 & -1 & 82.8 & 68.47 & 464.172 \\
\hline \multirow[t]{2}{*}{2} & 1 & 1 & 0 & 8 & 68.88 & 663.563 \\
\hline & & & & 6.8 & & \\
\hline 3 & 0 & 0 & 0 & 85 & 88.18 & 609.211 \\
\hline 4 & 0 & 0 & 0 & 85 & 88.18 & 609.211 \\
\hline 5 & 1 & 0 & -1 & 83 & 81.74 & 471.391 \\
\hline 6 & 0 & 1 & -1 & 76 & 56.96 & 378.227 \\
\hline 7 & -1 & -1 & 0 & 94 & 80.30 & 446.452 \\
\hline 8 & -1 & 0 & 1 & 87 & 70.71 & 853.771 \\
\hline 9 & 1 & -1 & 0 & 89.6 & 81.8 & 436.582 \\
\hline 10 & 0 & 0 & 0 & 85 & 88.18 & 609.211 \\
\hline 11 & 0 & 1 & 1 & 79 & 72.48 & 923.211 \\
\hline 12 & 0 & 0 & 0 & 85 & 88.18 & 609.211 \\
\hline 13 & -1 & 1 & 0 & 82 & 62.97 & 686.98 \\
\hline 14 & 1 & 0 & 1 & 93 & 78.52 & 869.236 \\
\hline 15 & 0 & -1 & -1 & 84.6 & 87.61 & 395.606 \\
\hline 16 & 0 & 0 & 0 & 85 & 88.18 & 609.211 \\
\hline 17 & 0 & -1 & 1 & 92 & 84.64 & 600.834 \\
\hline
\end{tabular}

Independent variables

Level used, actual (coded)

\begin{tabular}{lccc}
\cline { 2 - 4 } & Low $(-1)$ & Medium $(1)$ & High $(+1)$ \\
\hline Drug & 250 & 375 & 500 \\
Polymer & 250 & 375 & 500 \\
\hline Solvent & 2.5 & 5 & 7.2 \\
\hline
\end{tabular}

Table 2. Polynomial mathematical model data

\section{Coefficient code Second-order Polynomial coefficients for response variables}




\begin{tabular}{lccc}
\hline & \%EE & \%CDR & Particle size \\
\hline $\boldsymbol{\beta}_{\mathbf{0}}$ & 85 & 88.18 & 609.211 \\
\hline $\boldsymbol{\beta}_{\mathbf{1}}$ & 0.825 & 3.5275 & -0.07537 \\
\hline $\boldsymbol{\beta}_{\mathbf{2}}$ & -4.55 & -9.1325 & 96.58588 \\
\hline $\boldsymbol{\beta}_{\mathbf{3}}$ & 3.075 & 1.4125 & 193.4795 \\
\hline $\boldsymbol{\beta}_{\mathbf{1 1}}$ & 2.3 & 1.1025 & -3.38675 \\
\hline $\boldsymbol{\beta}_{\mathbf{2 2}}$ & 1.45 & -1.2975 & 4.5615 \\
\hline $\boldsymbol{\beta}_{\mathbf{3 3}}$ & -1.1 & 4.6225 & 84.984 \\
\hline $\boldsymbol{\beta}_{\mathbf{1 2}}$ & 3.325 & -7.59375 & 20.90563 \\
\hline $\boldsymbol{\beta}_{\mathbf{1 3}}$ & -0.225 & -7.09875 & -71.7224 \\
\hline $\boldsymbol{\beta}_{\mathbf{2 3}}$ & -1.875 & -5.65875 & 37.02588 \\
\hline $\mathbf{R}^{\mathbf{2}}$ & 0.9234 & 0.9060 & 0.9784 \\
\hline & & & \\
\hline & & & \\
\hline & & & \\
\hline
\end{tabular}

Table 3. Constraints for numeric optimization and predicted solutions

\begin{tabular}{lcccc}
\hline \multicolumn{1}{c}{ Variable } & Goal & $\begin{array}{c}\text { Lower } \\
\text { limit }\end{array}$ & Upper limit & Importance \\
\hline Drug (A) & In range & -1 & 1 & $* * *$ \\
\hline Polymer (B) & In range & -1 & 1 & $* * *$ \\
\hline Solvent (C) & In range & -1 & 1 & $* * *$ \\
\hline$\%$ EE & In range & 85.00 & 94.00 & $* * *$ \\
\hline$\% \mathrm{CDR}$ & In range & 56.96 & 88.18 & $* * * *$ \\
\hline Particle size & In range & 378.22 & 923.39 & \\
\hline
\end{tabular}
A
B
C $\% \mathrm{EE}$ 
Table 4. Various evaluation parameters of matrix tablets

\begin{tabular}{cc}
\hline Parameter & Value \\
\hline Average weight $(\mathrm{n}=20) \mathrm{mg}$ & $499.65 \pm 1.35$ \\
\hline Friability test $(\%)(\mathrm{n}=10)$ & $0.69 \pm 0.23 \%$ \\
\hline Hardness $(\mathrm{n}=5)\left(\mathrm{Kg} / \mathrm{cm}^{2}\right)$ & $4.13 \pm 0.13$ \\
\hline
\end{tabular}

Table 5. Regression cofficient values of microsponge matrix tablet and microsponge formulation

\begin{tabular}{ccc}
\hline Kinetic models & $\begin{array}{c}\text { Regression cofficient }\left(\mathbf{r}^{\mathbf{2}}\right) \\
\text { Matrix tablet }\end{array}$ & $\begin{array}{c}\text { Regression cofficient }\left(\mathbf{r}^{\mathbf{2}}\right) \\
\text { Microsponge formulation }\end{array}$ \\
\hline Zero order kinetic & 0.9547 & 0.9691 \\
\hline First order kinetic & 0.8339 & 0.5933 \\
\hline Higuchi model & 0.735 & 0.8631 \\
\hline Peppas model & 0.9894 & 0.7661
\end{tabular}

Table 6. Macroscopic evaluation of colonic lesions of rat

\begin{tabular}{cccccc}
\hline Groups & $\mathbf{0}$ & $\mathbf{0 . 5}$ & $\mathbf{1}$ & $\mathbf{1 . 5}$ & $\mathbf{2}$ \\
\hline Control & - & 1 & 2 & 5 & 1 \\
\hline Resveratrol & - & 1 & - & 2 & - \\
\hline Microsponge & - & 2 & 1 & - & - \\
\hline Matrix Tablet & - & 3 & 2 & - & - \\
\hline
\end{tabular}

